\title{
DEVELOPMENT OF HIGH QUALITY GRADES PRODUCTION TECHNIQUES USING A VOD PLANT AT VOESTALPINE GIESSEREI LINZ*
}

\author{
Andrea Pezza ${ }^{1}$ \\ José David Martínez Cerezo² \\ Alexander Tubikanec ${ }^{3}$
}

\begin{abstract}
The steel market is experiencing a difficult conjuncture: on the one hand steel producers minimize their investments while optimizing their over-production, on the other hand suppliers reduce their internal human resources and capacity in order to overcome the instability of the new era. A return to the steel production levels of the past is not expected in the short term. Research, development and plant concept optimization is one recipe to drive the future of the steel business. This article describes a new concept for a VOD plant developed as a result of thorough investigation and assessment of all possible solutions. A joint and tight cooperation with the final customer was necessary to reaching important results. This article consists of the contributions from the plant suppliers in terms of their experience and feedback, as well as the final user's. The final customer, voestalpine Giesserei Linz $\mathrm{GmbH}$, and the plant supplier, Primetals Technologies, are both worldwide players and highly focused on reaching best quality and innovation.

The article describes in detail a project that marks a change in the use of vacuum technologies for tank degassers.
\end{abstract}

Keywords: Vacuum technology, VOD, Safety, Innovation, Mechanical pump.

Process Engineer, Primetals Technologies Germany GmbH, Legelshurst, Germany.

Vacuum Pump Engineer, Primetals Technologies Germany GmbH, Legelshurst, Germany.

Plant Manager, voestalpine Giesserei Linz GmbH, Linz, Austria 


\section{Process}

As it is well known the VOD process consists of carbon reduction in combination with the minimization of the cost of Fe-alloy usage. The process is divided in dedicated steps; the various phases require a proper combination of different operational set points: vacuum pressure level, oxygen blowing set points, oxygen blowing distance from the steel bath, argon stirring rate. (See figure 1)

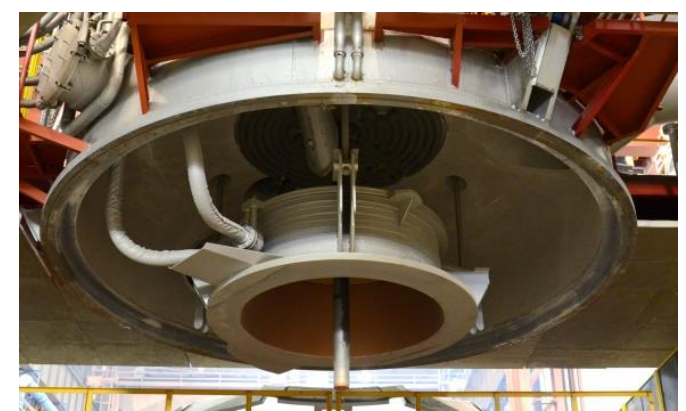

Figure 1 - VOD - Vacuum tank cover equipment

The set points are partially standardized and mostly a result of the operators' experience. The plant in Linz is a small sized unit with a challenging design: the VTD/VOD is able to handle 13 different ladle sizes with a steel weight ranging from 15 to 50t. The different steel levels, in accordance to the freeboard, required dedicated solution to allow the use of proper process parameters during the oxygen blowing phase and the use of automatic temperature, sampling and slag breaker manipulators.

The tank is a travelling tank with a fixed cover able to lift and lower when the tank is in treatment position. An alloy bin system with the possibility of alloying under vacuum is also part of the plant. A wide range of steel grades are produced requiring simple degassing or high alloyed grades decarburization under vacuum. The simple base used as a starting point for the designing of the whole plant was the lance oxygen blowing capacity in combination with a proper vacuum pump capacity. Moreover, a higher oxygen blowing range was preferred in order to cover the wider ladle size range, with more lances installed at the plant. The oxygen flow capacity of each lance meets the limits of the next lance in order to maximize the flow range. Minimizing the ladle splashes and obtaining maximum efficiency is the main goal.

The oxygen lance blowing distance from the steel surface was the object of debate and required comparing the experiences gathered at different plants in Europe. In order to keep all parameters under control, it was decided not to move the lance during the different process phases, but instead to optimize a single position that respects the oxygen supersonic flow shape and the steel penetration depth. This is quite a different approach in comparison to the typical VOD operations. Freezing this set point helped improving the plant efficiency because a lower number of process parameters remains to be set.

It has been proofed that lance distance from the steel bath and minimum ladle free board requirements alone cannot completely reduce the consequences of steel splashes. If a water cooled ladle cover is in use, a certain skull formation will always be inevitable and will have to be handled at the end of the treatment. While the refractory solution is still quite practical, financially it is not always the best option, due to the cost of cover changes and of the refractory. On the other hand, the water cooled solution has minimum maintenance requirements and allows producing 
thousands of heats without cover changes, (the 120t VD plant in Uralstahl, for example, produced 9000 heats with a Cu-plated solution).

The water cooled lance did not present any problems of skull formation around the lance tip, which is typically very difficult to handle, as experienced by various customers. The highlight of the three holes lance is the Laval nozzle design and exit angle. Several tests were conducted in the past and different angles were applied: from 7 to 10 degrees. An optimum solution was found for the voestalpine Giesserei plant.

Considering that more lances have to be used and exchanged during the VOD production campaign, the lance exchange has been optimized and the exchanging time is $<15$ minutes. The lance is exchanged together with the stuffing box. Different lances are stored close to the lance manipulator.

The oxygen lance stuffing box is integrated with different plant parts as the alloying system and the camera; all tank cover connections have been accurately designed in order to minimize the plant overall air leakages. Less than $10 \mathrm{~kg} / \mathrm{h}$ have been obtained during the plant commissioning and is also maintained after long time of operation. The leakage rate is controlled using the off gas flow measurement, a very good and revolutionary method. (See figure 2)

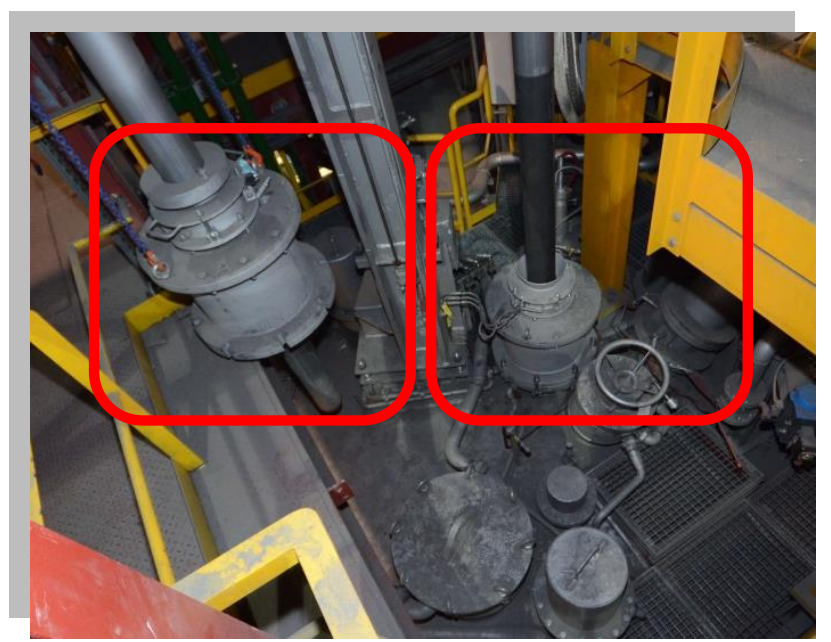

Figure 2 - Oxygen lance stuffing boxes

The stirring rate during decarburization, the main process phase, is difficult to set by use of a mathematical model, considering that during the oxygen blowing phase the internal camera view is darkened due to fume dust. The set points for the bottom stirring associated to the different steel grade families are listed in the level 2 database; however, they must be verified by the operator according to the plug conditions and must be visually set before starting the oxygen blowing phase. A dedicated parametric model has been developed in order to set the different flow in accordance to the different heat sizes.

All these kind of process parameters are stored, maintained and used by the level 2 system. This feature was also developed jointly, based on the experience and knowledge of voestalpine Giesserei. A dedicated process phase control model designed at the converter lines in Linz has been used and adapted for the VOD. With this process phase control model the operator has the complete overview of the different alternatives he can choose from. The process phases are connected with a logic function and the active pause is graphically highlighted. Bubbles and lines are the graphical links to easy and manageable operations. 
The vacuum pressure set point for each blowing phase is the main process parameter; the decarburization reaction is driven in relation to the balance between $\mathrm{Cr} / \mathrm{C} / \mathrm{O}$ oxidation, steel temperature, chromium and nickel content. At voestalpine Giesserei plant the minimum oxygen blowing pressure is limited to $50 \mathrm{mbar}$ in consideration of the plant safety concept. When the steam ejector pumps are used, no limitations are given. For some steel grades, such as super ferritic grades, blowing oxygen at very low pressure level is of fundamental importance.

A simple structure of different phases and working points needed to build up the process concept of the VOD is shown in the table below:

\begin{tabular}{|c|c|c|c|c|c|c|c|c|c|c|c|c|c|}
\hline \multicolumn{14}{|c|}{ VOD PROCESS PHASES } \\
\hline Steel quality family & Preparation & Decarb phase & Decarb phase & Decarb phase & Decarb phase & Decarb phase & Decarb phase & Decarb phase & Decarb phase & Decarb phase & VCD & RED & LEG \\
\hline$\langle 13,00 \mathrm{Cr} \%$ & \multirow{5}{*}{ TIME } & FIRST DEOX & CRITICAL Carbon & Intermediate phase & End blowing $\mathrm{C}$ & & & & & & \multirow{5}{*}{ TIME } & \multirow{5}{*}{ TIME } & \multirow{5}{*}{ TIME } \\
\hline$\langle 15,00 \mathrm{Cr} \%$ & & FIRST DEOX & CRITICAL Carbon & & Intermediate phase & End blowing $\mathrm{C}$ & & & & & & & \\
\hline$\langle 17,00 \mathrm{Cr} \%$ & & & FIRST DEOX & CRITICAL Carbon & & Intermediate phase & Intermediate phase & End blowing $\mathrm{C}$ & & & & & \\
\hline$\langle 19,00$ Cr\% & & & FIRST DEOX & CRITICAL Carbon & Intermediate phase & & Intermediate phase & Intermediate phase & End blowing $\mathrm{C}$ & & & & \\
\hline$\langle 21,00$ Cr\% & & & FIRST DEOX & CRITICAL Carbon & Intermediate phase & & Intermediate phase & Intermediate phase & & End blowing $\mathrm{C}$ & & & \\
\hline \multirow{4}{*}{$\begin{array}{c}\text { Process main } \\
\text { parameters }\end{array}$} & & \multicolumn{8}{|c|}{ LANCE FLOW } & & & & \\
\hline & & \multicolumn{12}{|c|}{ O2 LANCE DISTANCE FROM Steel BATH } \\
\hline & & \multirow{2}{*}{\multicolumn{12}{|c|}{ VACUUM PRESSURE SET POINTS }} \\
\hline & & & & & & \multicolumn{8}{|c|}{ BOTTOM STIRRING SET POINTS } \\
\hline
\end{tabular}

Table 1 - VOD process parameters

The operational concept described above allows reaching a manageable and stable process with narrow deviation in the metallurgical results obtained. The decarburization phase is controlled using the off gas analyser and, to a certain extent, in combination with the off gas flow rate. Recent developments in the off gas flow measuring are based on the use of the stable working point typical of the mechanical vacuum pump. Encouraging results have been obtained and a proper model is under construction.

Interesting results have been obtained in the production of high purity grades, with a carbon level $<10 \mathrm{ppm}$ without having to use the oxygen blowing lance. A deep vacuum time lower than 30 minutes is required. This kind of value is typically reached in $\mathrm{RH}$ plants.

The typical process route between the melting unit and the casting facilities has also been revised. Treatment at the ladle furnace facilities before and/or after the VOD is performed in accordance to the different steel grades to be produced. A new designing concept has placed the VOD in between the primary melting unit and the ladle furnace, especially when a decarburization process is required, thus achieving remarkable advantages in terms of energy saving and higher productivity.

Due to the peculiar characteristics of the plant, voestalpine Giesserei needed to be able to charge the alloy material under vacuum in three different ways, i.e. either via an automatic belt system connected to a classical bin system, or via a hopper properly designed to be handled by the overhead crane or alternatively via manual addition. This configuration allows maximum flexibility, a minimum amount of additions of material (in terms of kilo range) and avoids material with hygroscopic characteristics to be stored in the bin system. The vacuum hopper charging point is the same for all of the three ways. A dedicated monitoring system has been developed in order to avoid plant parts collision and any risks for human beings.

A safety matrix based on the action/ reaction principle has been used in accordance with the plant safety concept applying in case of risk. The system was checked and approved by a third certified authority.

The use of small ladles and discontinuous production result in high temperature losses that require fast process handling. Temperature and sampling sequences have been automated; alloy additions as well as all plant operations have been 
optimized with the fundamental support of the experienced plant users. A TV camera system offering an overview of all critical and important areas of the plant is nowadays a fundamental tool for plant operation and only requires one operator to manage it. One of the prerequisites for the design of the voestalpine Giesserei plant was that only two operators are available and they must be able to run the plant in normal as well as in any other critical conditions.

The voestalpine Giesserei VOD plant is not running continuously, the foundry production is based on high value products and much differentiated quality production. One of the main characteristics of the plant concept is low running costs and zero standby costs: these were obtained choosing a dry mechanical vacuum pump, as described below, and proper automation control. The plant is not guarded $24 \mathrm{~h}$ a day.

When the plant is in standby, it does not require any auxiliary part in operation and all the plant auxiliaries are connected only to the VOD plant. For example: machine cooling water circuit and hydraulic system. The machine cooling water circuit, on the contrary, must be kept in operation in case of low external temperature. Typical consumption for VOD heats are the following:

\begin{tabular}{|l|l|}
\hline Electrical energy & $6,5-10,0 \mathrm{kWh} / \mathrm{t}$ \\
\hline Oxygen & $5,5 \mathrm{Nm}^{3} / \mathrm{t}$ \\
\hline Nitrogen Stirring & $0,10 \mathrm{Nm}^{3} / \mathrm{t}$ \\
\hline Argon & $0,08 \mathrm{Nm}^{3} / \mathrm{t}$ \\
\hline Nitrogen flooding-flushing & $2,4-4,0 \mathrm{Nm}^{3} / \mathrm{t}(30-50 \mathrm{t})$ \\
\hline & \\
\hline Reduction material & \\
\hline Fe-Si reduction & $2,0 \mathrm{~kg} / \mathrm{t}$ \\
\hline FeSi-Alloying & $3,4 \mathrm{~kg} / \mathrm{t}$ \\
\hline Lime & $10,0 \mathrm{~kg} / \mathrm{t}$ \\
\hline Synthetic slag & $4,0 \mathrm{~kg} / \mathrm{t}$ \\
\hline
\end{tabular}

Table 2 - Main consumption parameters

\section{Design aspects and observations on vacuum pump}

One of the major points in the actual development is the use of mechanical vacuum pumps for the production of high quality steel grades. The plant in Linz belongs to be first ones worldwide to manage VOD operations with dry mechanical pumps and it is in accordance with ATEX regulations in Europe. As observed during operation, the final pressure achieved (usually below $1 \mathrm{mbar}$ ) and the speed of the process were not affected by the use of mechanical vacuum system.

The vacuum pump accepts off-gas temperature $<60{ }^{\circ} \mathrm{C}$. The off gas temperature is controlled using:

- a Cu-cladded roof over the ladle,

- water cooled panels in the cover system,

- part of the suction line leaving the cover is water cooled, an off-gas cooler, pipe bundle type, is used during oxygen blowing operation and pump down phases,

- a dust filter (with more than $400 \mathrm{~m}^{2}$ filtering surface) protects the dry mechanical pump against dust. 
The core part of the VOD is the mechanical pump divided in 4 stages (Figure 3) 0 : the first 3 stages are connected to the tank by means of Roots blower the last stage is connected to atmosphere has a series of rotary screw pumps

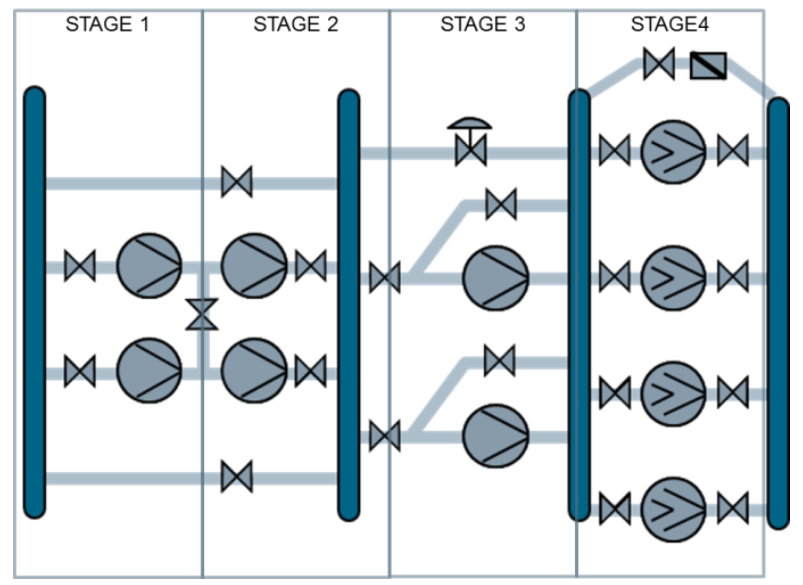

Figure 3 - Schematic vacuum pump configuration

The suction capacity for different working point is as follows:

80,000 m³/h@0,67mbar

13,000 m³/h@100mbar

During the degassing process, the load of gas coming from the metallurgical process is relatively low and no thermal loads have to be dissipated. This type of process allows a minor cooling in the vacuum pump system, which is a right approach for pure degassing purposes. However, during oxygen blowing operation in the VOD process, the amount of gas generated is much higher (from the order of magnitude of the oxygen blown) and an intermediate gas cooler needs to be foreseen between compression stages in the vacuum pump.

In this case the vacuum pump is built with inter-stage coolers between each vacuum stage. The values of gas inlet and outlet temperature at each stage during a typical VOD operation are represented on Figure 4.

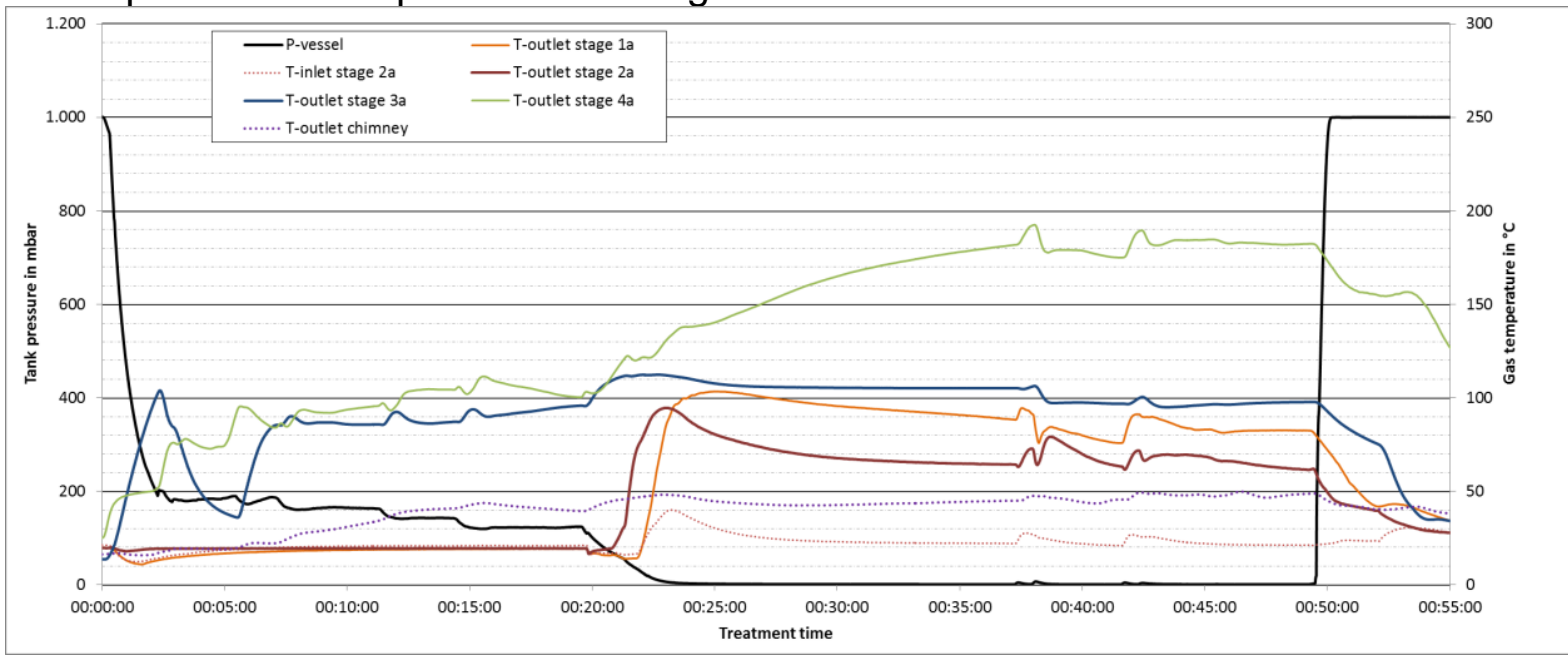

Figure 4 - Vacuum pumps inter-stages temperature and pressure profiles during VOD treatment 
During VOD operation, due to the fact that the pump is not working at its maximum load, temperatures are lower than those observed during pump down. This is especially true for stage 3 which expresses the suction capacity during the oxygen blowing phase.

The highest gas temperature is present at the outlet of the last stage (screw pump) where the highest compression ratio is performed (1:85 up to 1:100, i.e. 10-12 mbar inlet with 1000 mbar outlet pressure). However in this case the mass flow is very low (the off-gas flow is below $100 \mathrm{Nm}^{3} / \mathrm{h}$ ) and a cooling effect is already present in the chimney reaching always values below $50^{\circ} \mathrm{C}$. For the other pumps (root type) the highest temperatures are reached during pump down for a short period of time.

In terms of design, the most critical working point is between stage 1 and stage 2 because the balance between pressure drop and gas cooling has a big influence (see Figure 5 - Vacuum pump stages 1 and 2 with inter-stage cooling and redundancy connection. An oversized gas cooler as opposed to a better gas cooling can generate a high pressure drop (in this area the volume flow is approximately $1 / 4$ of the suction capacity, which means approximately $20,000 \mathrm{~m}^{3} / \mathrm{h}$ during deep vacuum operation). Such balance has been reached as a combination of low pressure drop and inlet temperatures at stage 2 lower than those required by the manufacturer. The inlet temperature at stage 2 is the only one from the inter-stage cooling indicated in the figure, as it is representative of the temperature rise; as expected, the peak at this stage is reached at pump down start. At other inter-stage cooling times the inlet temperatures measured are lower than $30^{\circ} \mathrm{C}$ during the complete operation and they are not shown in the graphic.

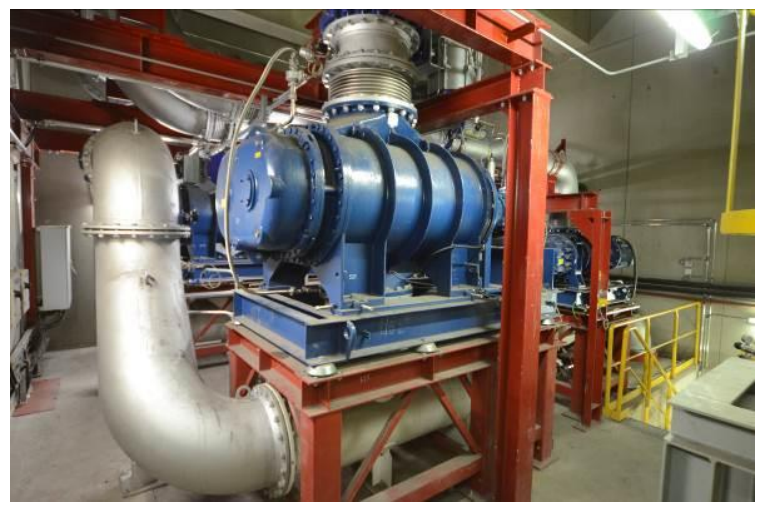

Figure 5 - Vacuum pump stages 1 and 2 with inter-stage cooling and redundancy connection

For VD and $\mathrm{RH}$ operation the setting requirements are lower and usually only consist in slowing the pump down ramp in order to reduce splashes to the cover/vessel. For VOD operation a pressure setting system is required where pressure can be maintained for several minutes, irrespective of the load. In steam ejector vacuum pumps typically it has been used either a steam nozzle regulating the driving force i.e. the steam flow - or a by-pass line, where the off-gas is recirculated to give additional load to the pump.

In the voestalpine Giesserei plant two regulation concepts have been used as illustrated in Figure 6. During VOD operation only stages 3 and 4 are working. For low vacuum suction capacity requirements only the last compression stage, that of the screw pumps, is working with regulated frequency (see point 1 in the figure below). In this case the third compression stage, that of the roots pumps, is running 
without load, i.e. it is by-passed. That can be recognized as the vessel pressure is the same as the inlet pressure of the screw pumps (stage 4).

As the suction capacity required increases, the third compression stage goes into operation, with stages 3 and 4 working in line. Where a higher suction capacity is required, the regulation line of stage 3 needs adjusting the recirculation load and pressure (see point 2 in the figure). Once the regulation line is fully opened, then the frequency on the screw pumps is lowered (see point 3 in the figure).

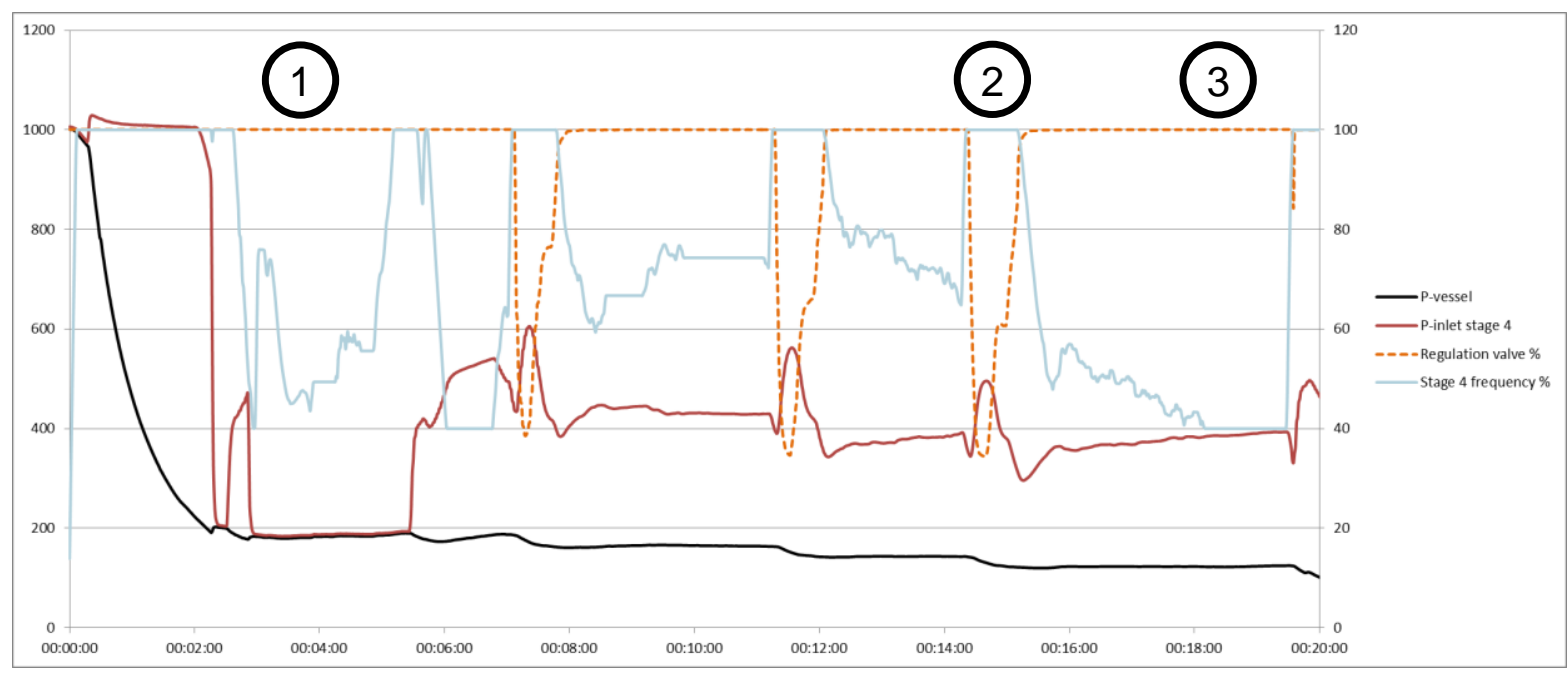

Figure 6 - Vacuum pressure regulation control trends

As far as safety is concerned, the additional requirement involves a higher presence of carbon monoxide than the usual vacuum degassing system. That means that explosive mixtures can be generated if the leak rate of the system is high or the oxygen blown is not reacting with the steel (which is more likely to happen during the $\mathrm{RH}$ process).

ATEX classification of gases from VD/VOD process 00

\begin{tabular}{|l|l|l|}
\hline Gas & Gas group & $\begin{array}{l}\text { Temperature class } \\
(\text { max. temperature surface })\end{array}$ \\
\hline Hydrogen & IIC & $\mathrm{T} 1\left(<450^{\circ} \mathrm{C}\right)$ \\
\hline Carbon monoxide & IIA/B & $\mathrm{T} 1\left(<450^{\circ} \mathrm{C}\right)$ \\
\hline $\begin{array}{l}\text { Resulting } \\
\text { requirement }\end{array}$ & IIC & $\mathrm{T} 1\left(<450^{\circ} \mathrm{C}\right)$ \\
\hline
\end{tabular}

Table 3 - ATEX classification table

On the other hand the presence of oxygen can be controlled by reducing the leaks (although not during operation) or diluting it in such a way that the oxygen level is kept at its lowest, i.e. with a matching explosive percentage.

The main disadvantage in the VOD process as opposed to the degassing process is that the pressures at which the gas is produced (between $1-200$ mbar) can lead to an overpressure output. Therefore, the vacuum pump uses ATEX version of the vacuum pumps in the last 2 stages (the only ones used during the oxygen blowing phase) and does not represent a danger to the equipment or the safety of workers.

In order to overcome the $\mathrm{CO}$ poisoning risk as well as the risk of formation of explosive mixtures in the pump room, the system is equipped with monitored forced ventilation and $\mathrm{CO}$ detectors in the pump room which activate alarm signals in both 
control pulpit and pump room entry. Alarms are supervised by the fire brigade group, whereas the plant operators have no possibility of interfering with them. At any rate, that kind of safety concern only applies from the exhaust gas line onwards (exit of stages 3 and 4 and off-gas line), as vacuum prevents the gas from flowing to the pump room.

Another safety/health concern is the noise emission of the vacuum pump. Typically vacuum pump manufacturers state the values recorded at their lowest vacuum level, which can lead to misunderstandings when it comes to the required noise protection. Due to the unsteady operation of the vacuum pump, noise emissions are extremely variable, resulting in the manufacturers' values being lower than the actual measured value. The highest noise level recorded was around $95 \mathrm{~dB}$ achieved at the first stages of pump down, i.e. when the vacuum vessel is evacuated. However, the use of additional noise protective equipment suffices in the very rare occasions when works such as inspections of the measurement indicators, need performing during pump operation.

Typical water quality requirements from vacuum pump suppliers are slightly tougher in terms of trace elements and suspended particles compared to the usual machine cooling water used in steel plants. Failing to consider this indication can lead to malfunctions of the vacuum pumps and translate into higher maintenance efforts. An example of a damaged cooling water circuit due to the use of bad quality water can be observed in Figure 7, the picture is related to a different pump type installed in a 100t VD plant for a Mexican customer.

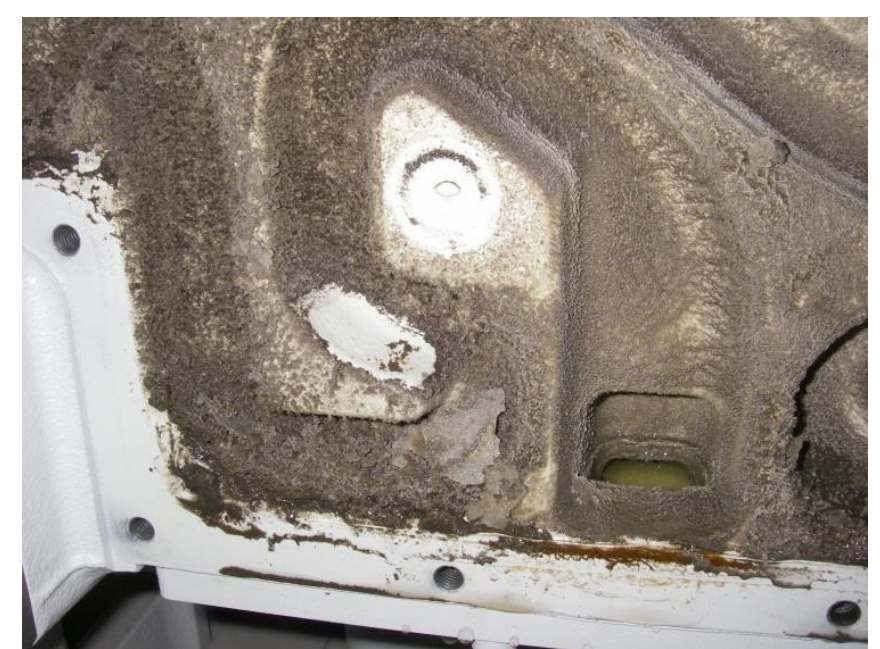

Figure 7 - Inner vacuum pump water cooled channels

At voestalpine Giesserei plant a separate cooling water system is used for the vacuum pump thus avoiding this sort of problems. As it can be observed in Figure 8 Vacuum pump water cooling stationthe complete water circuit is independent, thus maintain the water quality requirements for the vacuum pump quite easily. In order to get this low temperature in the heat exchanger a lower inlet temperature is required, a maximum temperature of $20^{\circ} \mathrm{C}$ is ensured with the installed system. 


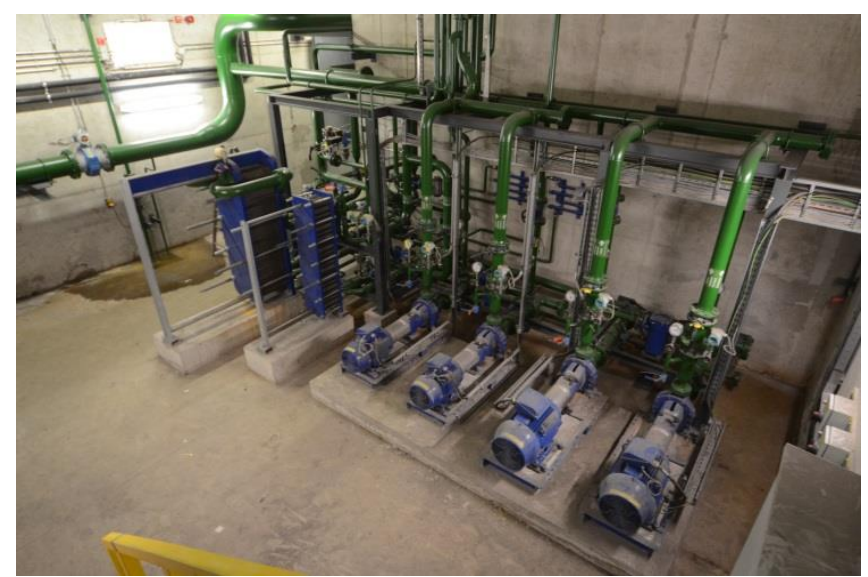

Figure 8 - Vacuum pump water cooling station

\section{Conclusions}

A VOD plant for the production of high quality grades remains a valid solution for achieving best quality and best operational costs. Combining carbon removal and degassing operation is fundamental for all major quality grades. The typical plant layout also needs reviewing in order to optimize the VOD plant capability and reduce the energy cost.

A major role in this respect is played by the development of a proper safety concept for the whole plant and especially for the dry mechanical vacuum pump.

The operation of the plant is fully automated thus reducing the human factor support. With regards to the mechanical vacuum pump: inter-stage cooling must be foreseen for VOD operation as confirmed by operational results. A regulation concept is required for a vacuum pump system starting from $20 \%$ of the suction capacity. Frequency regulation at screw pumps has been observed as a smooth regulation.

\section{References}

Pezza, Andrea et al. - The challenge of using mechanical pump systems for VOD operation (Aistech Procedings 2014)

Alireza Bahadori; Hazardous area classification in petroleum and chemical plants - A guide to mitigating risk

Bartknecht, Wolfgang: Explosionsschutz - Grundlagen und Anwendung 